\title{
Aging of HDPE Pipes Exposed to Diesel Lubricant
}

\author{
Amelia H. U. Torres' ${ }^{1}$, José R. M. d'Almeida', and Jean-Pierre Habas ${ }^{2}$ \\ 1: Departamento de Ciencia dos Materiais e Metalurgia, Rua Marquês de São \\ Vicente, Gavea, Rio de Janeiro - RJ, Brasil \\ 2 : Laboratoire de Physico-Chimie des Polymères, CNRS-UMR, Université de Pau et \\ des Pays de l'Adour, Pau, France
}

\begin{abstract}
The effects caused upon the physicochemical behavior of high-density polyethylene pipes by exposure to a diesel lubricant were investigated, as a function of time and temperature, by thermogravimetric and gravimetric analysis and by FTIR. The gravimetric data were satisfactorily described using Fick's law. The fitting of the experimental points showed that diesel, which can be regarded as a model fluid to analyze the effects caused by aromatic unities present in oil derivatives, has a high diffusion rate into HDPE. The FT-IR results showed that no main structural modifications have occurred after exposure, besides solubilization of low molecular weight units. From the analysis performed, physical aging was identified as the aging process occurring when the HDPE pipes came in contact with diesel lubricant.
\end{abstract}

\section{Keywords Aging; Diffusion; FTIR; HDPE; Oil derivatives; Pipes; Thermogravimetry}

\section{INTRODUCTION}

Nowadays, polymeric pipes are being considered as suitable materials to substitute for metallic pipes in the transportation of oil derivatives. Carbon steel is still the main material used to manufacture pipelines, but corrosion and a fairly high internal roughness are two main drawbacks of steel pipelines[1]. Therefore, the substitution of old steel grids by new ones using polymers or steel tubes with an inner polymeric layer, instead of an all-steel pipe is a common trend, since polymers are corrosion resistant and can also be manufactured with very small surface roughness. Among the many available polymeric materials, high density polyethylene (HDPE) is a natural choice due to its good properties, availability, and cost. Polymers, however, can also present deterioration of their properties when exposed to aggressive environments, such as those found when gas and oil derivatives are considered. Swelling, microcracking and plasticization are common problems related to the aging of polymers[2-6]. These phenomena are due to physical or chemical aging of the polymer. When fluids are in contact with a polymeric material, physical aging due to diffusion of the fluid into the polymer is frequently a problem, with the fluid diffusing into the free volume between the polymeric chains[7]. In this work, a study was undertaken to analyze the variation of the physical-chemical behavior of a HDPE pipe, as a function of the time and the temperature of exposure to diesel oil. This particular fluid was used in order to evaluate the effect of the presence of aromatic units on the aging medium. The effect of a fluid composed only by aliphatic units is reported elsewhere[8].

\section{EXPERIMENTAL PROCEDURES AND MATERIALS}

A commercial HDPE pipe was used in this work. Samples of both HDPE and diesel oil were characterized by Fast Fourier Infrared Spectroscopy (FT-IR) and by thermogravimetric analysis (TGA). The FT-IR analysis was performed using the ATR 
technique, so the samples could be analyzed without any special preparation. A Perkin-Elmer model Spectrum One equipped with a diamond/ZnSe crystal was used. The thermogravimetric analysis was performed with a TA Instruments Model TGA $\mathrm{Q} 50$, equipment, under nitrogen atmosphere, from $20^{\circ} \mathrm{C}$ to $550^{\circ} \mathrm{C}$, at a heating rate of $10^{\circ} \mathrm{C} / \mathrm{min}$. Specimens $80 \mathrm{~mm}$ long, $10 \mathrm{~mm}$ large and $2 \mathrm{~mm}$ thick were machined from the HDPE pipe, and were immersed in diesel using hermetically closed containers. These containers were put in air circulating ovens at two different temperatures $\left(20^{\circ} \mathrm{C}\right.$ and $\left.50^{\circ} \mathrm{C}\right)$, to evaluate the effect of the temperature upon the aging process. The specimens were maintained in immersion for times up to 150 days. Absorption of diesel by the polymer was evaluated by gravimetry. The weight gain vs. time of immersion curve of the specimens was obtained following the procedures described by the ASTM D570 standard for plastics. The samples were weighted at regular time intervals, within $0.0001 \mathrm{~g}$. In order to obtain reliable values, the following procedure was adopted after a very careful experimental analysis[9]: i) after a pre-established immersion time, the specimens were removed from the bath and were wiped with a dry cloth; ii) the samples were, then, left at rest for 20 minutes at the laboratory atmosphere. This resting time was experimentally determined as the time needed for the solvent to complete volatize from the surface of the specimens. Therefore, the weight gain of the sample reflects only the fluid diffused into the polymer. The experimental results were given using the relative mass variation of the sample, namely:

$$
\begin{aligned}
& \mathrm{M}_{\mathrm{s}}(\%)=\frac{\mathrm{M}_{\mathrm{w}}-\mathrm{M}_{\mathrm{o}}}{\mathrm{M}_{\mathrm{o}}} \times 100 \\
& M_{S}(\%)=\frac{M_{w}-M_{o}}{M_{o}} \times 100
\end{aligned}
$$

where $M_{w}$ is the mass of the polymer and of the diffused fluid at a given time $t$ and $M_{0}$ is the initial mass of the polymer. After 150 days, the specimens were removed from the

immersion bath and were analyzed using the same techniques and procedures formerly used to characterize the as-received materials, namely FT-IR and TGA.

\section{EXPERIMENTAL RESULTS}

Figure 1 shows the FT-IR spectra of the HDPE pipe and of the diesel. For both materials one can observe the 3 absorption bands related to the vibration modes of the $\mathrm{C}-\mathrm{H}$ bond, namely[10]: stretching occurring between 2950 and $2850 \mathrm{~cm}^{-1}$, bending (1350-1450 $\mathrm{cm}^{-1}$ ) and rocking, near $700 \mathrm{~cm}^{-1}$. One can also observe at Figure $1 a$ the presence of two large regions of absorbance. The first spectral domain occurring between $3200-3400 \mathrm{~cm}^{-1}$ is characteristic of the hydroxyl group, and can be associated to the presence of humidity at the pipe wall[5,11,12]. The second absorbance region is found between $1550-1700 \mathrm{~cm}^{-1}$ and indicates the presence of carbonyl units $(\mathrm{C}=\mathrm{O})$. These chemical groups are probably due to oxidation of the pipe during its manufacture by extrusion[12]. Besides the aforementioned $\mathrm{C}-\mathrm{H}$ absorption bands, the FT-IR spectrum of the diesel, Figure $1 b$, shows an absorption band at $1600 \mathrm{~cm}^{-1}$, also associated to carbonyl units, and a wide absorption region between 650 and $800 \mathrm{~cm}^{-1}$ characteristic of the $\mathrm{sp}^{2}$ vibration of $\mathrm{C}-\mathrm{H}$ bonds from the aromatic rings[10,13]. Figure 2 shows the thermogravimetric analysis for the unaged HDPE polymer and that for the diesel. It can be observed that only at $\sim 300^{\circ} \mathrm{C}$ the 
polymer begins to degrade $\left(\sim 1 \%\right.$ of weight loss). At $490^{\circ} \mathrm{C}$, the degradation process is almost finished, with a weight loss of nearly $99 \%$. The peak temperature where the degradation process is at its maximum rate occurs at $460^{\circ} \mathrm{C}$. These temperatures agree very well with values reported at the literature [14].

The main degradation process for this polymer under nitrogen atmosphere corresponds to the rupture of the macromolecular chains of the polymer into a series of alkanes and alkenes [15].

For the diesel (Figure $2 \mathrm{~b}$ ), the volatilization process begins at $58^{\circ} \mathrm{C}$, where it occurs a mass loss of $\sim 1 \%$. The evaporation is accelerated at $111^{\circ} \mathrm{C}$, with a peak temperature occurring at $200^{\circ} \mathrm{C}$. At $254^{\circ} \mathrm{C}$ the diesel is completely evaporated. As expected, the diesel evaporates at a much lower temperature than the beginning of the thermal degradation

process for the HDPE polymer. Figure 3 shows the gravimetric data obtained as a function of the immersion time and of the temperature of immersion. Two aspects must be highlighted:

i. The amount of diesel absorbed is relatively high, what agrees with the FT-IR analysis where it was observed that the chemical structures of both materials (HPDE and diesel) are similar. Since diffusion is a thermally activated process, both the saturation amount of absorbed fluid and the time needed to attain this saturation value varied with the immersion temperature. Saturation values of $8.4 \%$ and $6.7 \%$ where obtained when the polymer was immersed at $50^{\circ} \mathrm{C}$ and $20^{\circ} \mathrm{C}$, respectively. The time needed to reach these values was of, respectively, 14 and 45 days. A higher amount of absorbed fluid with the increase of temperature is related to the increase of the free volume with the temperature. Besides, the viscosity of the oil is also reduced at an increased temperature, contributing to ease its diffusion into the polymer.

ii. After the amount of absorbed fluid reaches a saturation value, the relative mass begins to decrease. After 150 days of immersion the relative weight of the polymer decreased to $6,8 \%$ and $6 \%$, for the temperatures of $50^{\circ} \mathrm{C}$ and $20^{\circ} \mathrm{C}$, respectively.

The gravimetric data were analyzed using the Fick model, to determine the diffusion coefficient of the diesel in the HDPE polymer at both temperatures of immersion.

The weight gain vs. the square root of the immersion time data points followed a straight line for short immersion times, agreeing very well with the predicted diffusion Fickian behavior[16]. The equation used to determine the diffusion coefficient was:

$$
D=\frac{\pi}{4} \frac{L^{2}}{t}\left(\frac{M_{t}}{M_{\infty}}\right)
$$

where $M_{t}$ is the mass of water absorbed at a time t, $M_{x}$ is the mass of water absorbed at saturation, $h$ is the thickness of the sample and $D$ is the diffusion coefficient. The values obtained were $1.06 \times 10^{-12} \mathrm{~m}^{2} \times \mathrm{s}^{-1}$ and $8.76 \times 10^{-12} \mathrm{~m}^{2} \times \mathrm{s} \mathrm{s}^{-1}$, respectively at $20^{\circ} \mathrm{C}$ and $50^{\circ} \mathrm{C}$. There is a large variation of values reported on the literature regarding diffusion coefficients of oils diffusing into several different media[17-19]. This behavior can be directly attributed to the different interaction of oils and polymers, depending on the solubility parameter and on the polymer structure[19]. The values obtained here seem to indicate a fairly high diffusion coefficient, which could be 
related to the similarities already observed by the FT-IR analysis of the chemical structure of HDPE and diesel oil.

Figure $4 a$ shows the thermogravimetric curve obtained for the HPDE polymer aged at $20^{\circ} \mathrm{C}$ during 35 days. The curves for the as-received HDPE and for the diesel are also shown as a reference. The aged HPDE presents a weight loss of $6.2 \%$ between 58 and $250^{\circ} \mathrm{C}$. This temperature is very close to the temperature at which the diesel is completely volatized (see Figure $2 b$ ). Therefore, this first weight loss can be attributed to evaporation of the diesel oil absorbed by the polymer. Besides, one can observe that the onset temperature and also the peak temperature, where the polymer begins to degrade due to the increasing temperature is not altered. These results are an indirect indication that a physical, rather than a chemical, interaction is occurring for the earlier absorption times. For an aging time of 84 days at $20^{\circ} \mathrm{C}$, Figure $4 b$, the weight loss due to diesel was higher, which agrees with the gravimetric data previously described (Figure 3 ). It is worth noticing, however, that the onset temperature was shifted to a higher value in respect to the one measured for the as-received HDPE polymer. For longer aging times ( $t>80$ days), the gravimetric analysis showed that the weight of the polymer decreased, after a saturation point has been achieved, Figure 3. To explain this behavior, two hypotheses can be considered. One can consider that desorption of the solvent is taking place or one can consider that solubilization and extraction of low molecular weight chains of the polymer is occurring. The thermogravimetric data are validating this second hypothesis, since the onset temperature, related to the beginning of thermal degradation of the polymer, was displaced to a higher value. In fact, the increase of the thermal stability of a polymer is known to be dependent of its average molecular weight, with higher thermal properties being associated to higher molecular weights[20]. This mechanism also agrees with the rheological characterization of this polymer, which shows that the as-received HPDE has a large distribution of molecular weights[9]. In respect to the effect of temperature, one can observe that the mass loss of the aged HDPE at $50^{\circ} \mathrm{C}(7.7 \%)$ was higher than that at $20^{\circ} \mathrm{C}(6.2 \%)$, when the temperature range below the onset temperature is considered, Figure 5. This result is close related to a higher diffusion coefficient of diesel at $50^{\circ} \mathrm{C}$. Therefore, more fluid is absorbed when the temperature is increased. From the spectroscopic analysis of the aged specimens it was possible to evaluate the changes produced at the macromolecular structure of the polymer due to its exposure to diesel oil. Figure 6 shows the FT-IR spectra obtained when the polymer was aged at $50^{\circ} \mathrm{C}$, as a function of the immersion time. It can be observed that the spectra before and after diesel absorption are similar, showing that the aging of the polymer by its immersion in diesel did not caused structural modifications of the polymer. The appearance of two small peaks situated at spectral regions characteristic of the diesel can also be observed, as a function of the immersion time, clearly indicating the absorption of the fluid by the polymer. Similar results were obtained when the polymer was aged at $20^{\circ} \mathrm{C}$, but the height of the peaks were smaller, since less fluid is absorbed at the lower aging temperature. Figure 7 shows a comparison of both spectra, showing the behavior jut described. The analysis of the FT-IR spectra did not show, however, the evolution of any new absorbance peak, indicating that the absorption of diesel did not caused chemical modifications on the macromolecular structure of the polymer. Therefore, and although low molecular weight chains were extracted for longer immersion times, physical aging is occurring between HDPE and diesel. 


\section{CONCLUSIONS}

The analysis performed showed that several factors influence the behavior of HDPE in respect to its aging by immersion in diesel. First, there is a temperature effect, and the gravimetric and thermogravimetric results showed that aging was more relevant at $50^{\circ} \mathrm{C}$. In particular, two phenomena were identified: diffusion of the fluid into the polymer and solubilization and extraction of low molecular weight chains. Second, there is the very important aspect of the fluid to polymer affinity, what contributes to the fairly high diffusion coefficients measured. The FT-IR analysis showed that the macromolecular structure of the polymer was not altered, even after long aging times, since the spectra of the polymer before and after aging were similar, without the evolution of any new peak that could not be associated to either the polymer or the diesel. It was concluded that both phenomena involved when HDPE is exposed to diesel oil, viz. diffusion and extraction of low molecular weight chains, are physical aging processes.

\section{ACKNOWLEDGEMENTS}

The authors acknowledge the financial support from the Brazilian funding Agency CNPq. 


\section{REFERENCES}

1. Choi, Y.-S.; Chung, M.-K.; Kim, J.-G. Effects of cyclic stress and insulation on the corrosion fatigue properties of thermally insulated pipeline. Mater. Sci. Eng. 2004, 384, 47-56.

2. Verdu, J. Effect of aging on the mechanical-properties of polymeric materials. J. Macromol. Sci. Pure Appl. Chem. 1994, A31, 1383-1398.

3. Schouwenaars, R.; Jacobo, V.H.; Ramos, E.; Ortiz, A. Slow crack growth and failure induced by manufacturing defects in HDPE-tubes. Eng. Fail. Anal. 2007, $14,1124-1134$.

4. Choi, B.-H.; Chudnovsky, A.; Paradkar, R.; Michie, W.; Zhou, Z.; Cham, P.-M. Experimental and theoretical investigation of stress corrosion crack (SCC) growth of polyethylene pipes. Polym. Degrad. Stabil. 2009, 94, 859-867.

5. Frank, A.; Pinter, G.; Lang, R.W. Prediction of the remaining lifetime of polyethylene pipes after up to 30 years in use. Polym. Test. 2009, 28, 737-745.

6. Zanasi, T.; Fabbri, E.; Pilati, F. Qualification of pipe-grade HDPEs: Part I, development of a suitable accelerated ageing method. Polym. Test. 2009, 28, 96102.

7. Struik, L.C.E. Mechanical behaviour and physical ageing of semicrystalline polymers: 4. Polymer 1989, 30, 815-830.

8. Torres, A.A.U.; d'Almeida, J.R.M.; Habas, J.P. Evaluation of the effect of a paraphinic oil on the physical-chemical behavior of HDPE pipes. Polímeros: Ciência e Tecnologia, submitted.

9. Torres, A.A.U. Physical-chemical aging of HDPE pipes used at transportation grids of oil derivatives, MSc Dissertation, Pontifícia Universidade Católica do Rio de Janeiro, 2007 (in Portuguese).

10. Stuart, B. Infrared Spectroscopy Fundamentals and Applications, John Wiley and Sons: New York, 2004.

11. Predoi-Cross, A.; Lees, R.M.; Johns, J.W.C. Fourier Transform Infrared Spectroscopy and vibrational coupling in the $\mathrm{OH}$-bending band of $13 \mathrm{CH} 3 \mathrm{OH}$. J. Mol. Spectrosc. 1998, 191, 348-361.

12. McDonough, L.A.; Chikan, V.; Zee, H.K.; Leone, S.R.; Hinsberg, W.D. Fourier transform infrared spectroscopy studies of waterpolymer interactions in chemically amplified photoresists. J. Vac. Sci. Technol. B 2005, 23, 344-348.

13. Jarviste, R.T.; Muoni, J.H.; Soone, H.J.; Riisalu, A.; Zaidentsal, L. Diesel fuel oxidation in storage. Solid Fuel Chem. 2008, 42, 123-127.

14. Apone, S.; Bongiovanni, R.; Braglia, M.; Scalia, D.; Priola, A. Effects of thermomechanical treatments on HDPE used for TLC ducts. Polym. Test. 2003, 22, 275-280.

15. Beyler, C.L.; Hirschler, M.M. Thermal decomposition of polymers. In: P.J. DiNenno (Ed.), SFPE Handbook of Fire Protection Engineering, 3rd Ed., National Fire Protection Association: Quincy, MA, 2002, Chapter 1-7, pp. 110-131.

16. Crank, J. The Mathematics of Diffusion, 2nd Ed., Clarendon Press, Oxford, UK, 1975.

17. Koszinowski, J. Diffusion and solubility of n-alkanes in polyolefins. J. Appl. Polym. Sci. 1986, 32, 4765-4786.

18. S,as,maz, D.A. Evaluation of the diffusion coefficient of rapeseed oil during solvent extraction with hexane. J. Amer. Oil Chem. Soc. 1996, 73, 669-671. 
19. Fouchet, B. Diffusion of mineral oil in styrene-butadiene polymer films. J. Appl. Polym. Sci. 2009, 111, 2886-2891.

20. Madras, G.; Chung, G.Y.; Smith, J.M.; McCoy, B.J. Molecular weight effect on the dynamics of polystyrene degradation. Ind. Eng.Chem. Res. 1997, 36, 20192024. 


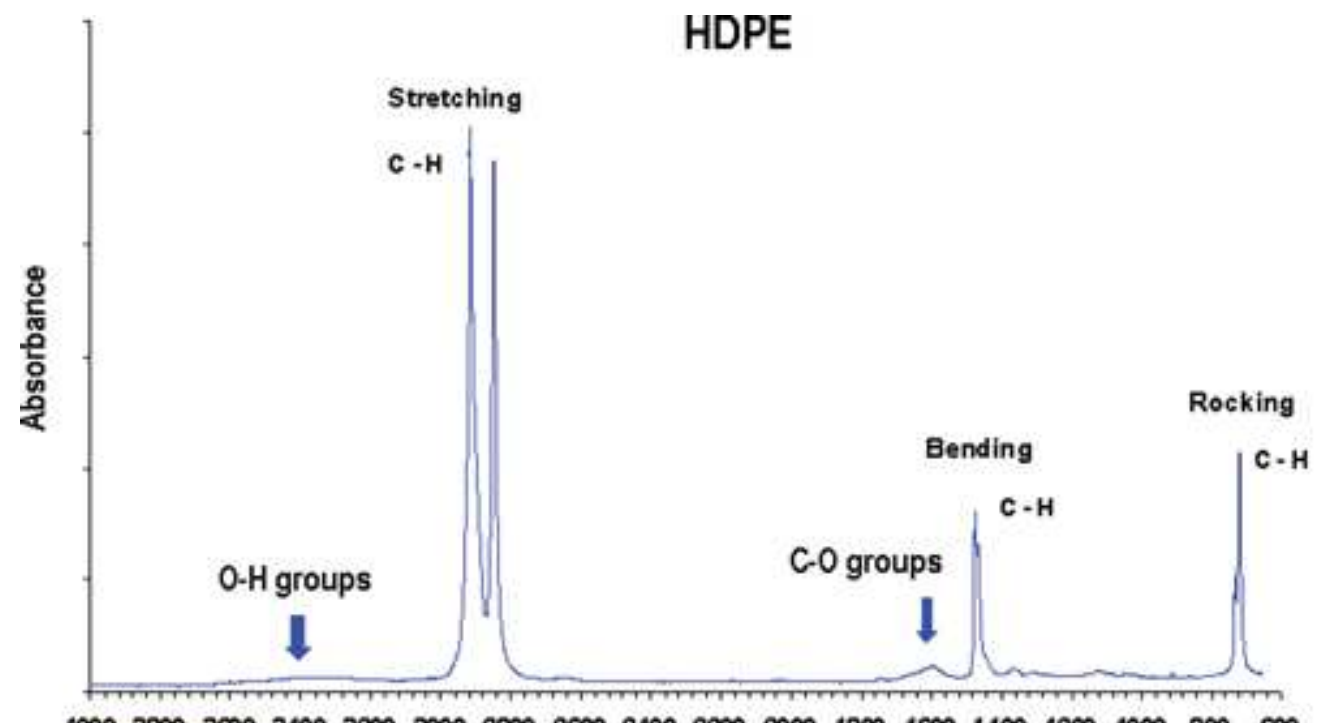

$\begin{array}{lllllllllllllllllllll}4000 & 3800 & 3600 & 3400 & 3200 & 3000 & 2800 & 2600 & 2400 & 2200 & 2000 & 1800 & 1600 & 1400 & 1200 & 1000 & 800 & 600\end{array}$

Wave number $\left(\mathrm{cm}^{-1}\right)$

(a)

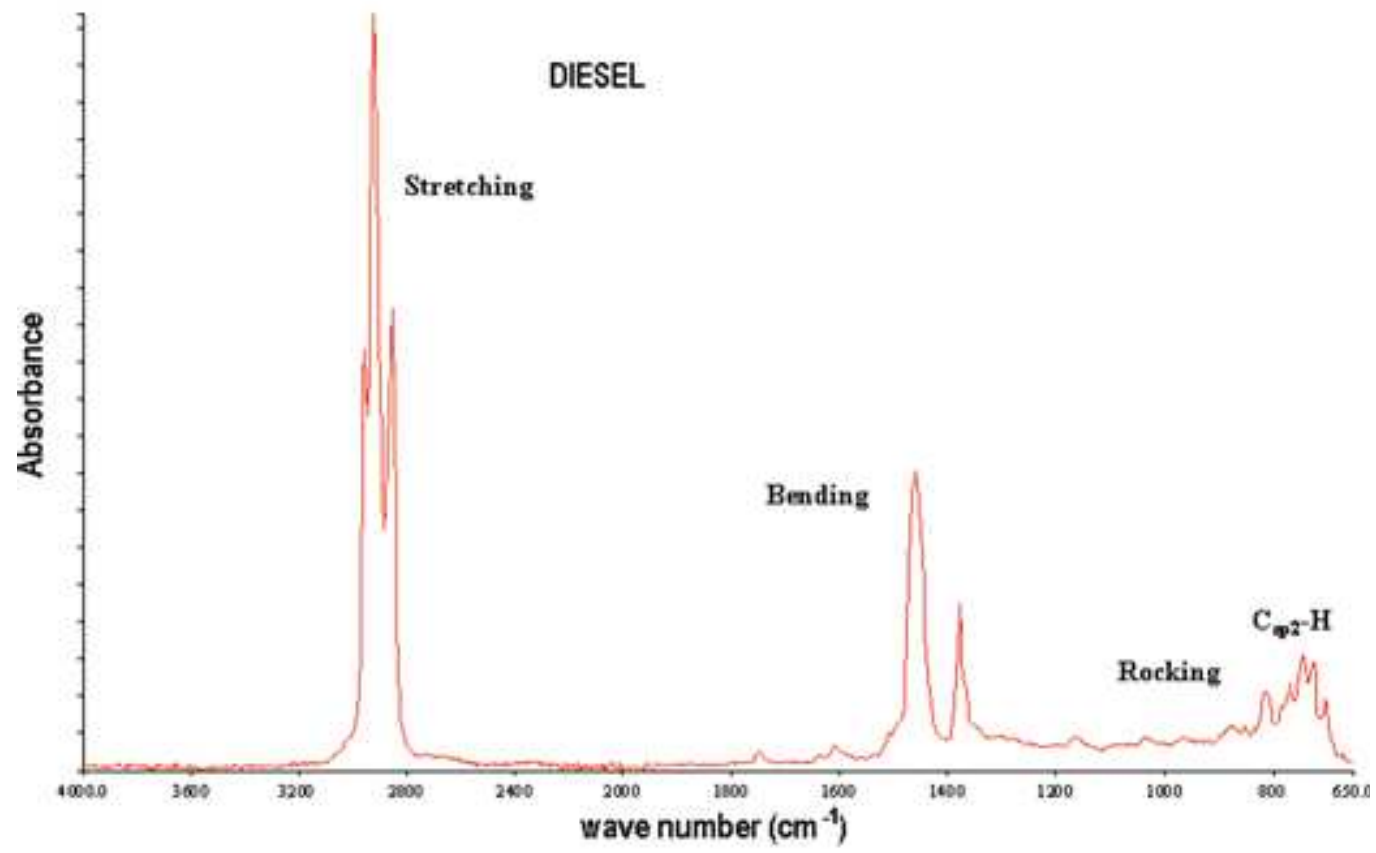

(b)

FIG. 1. FT-IR analysis of (a) HDPE pipe and (b) diesel oil. 


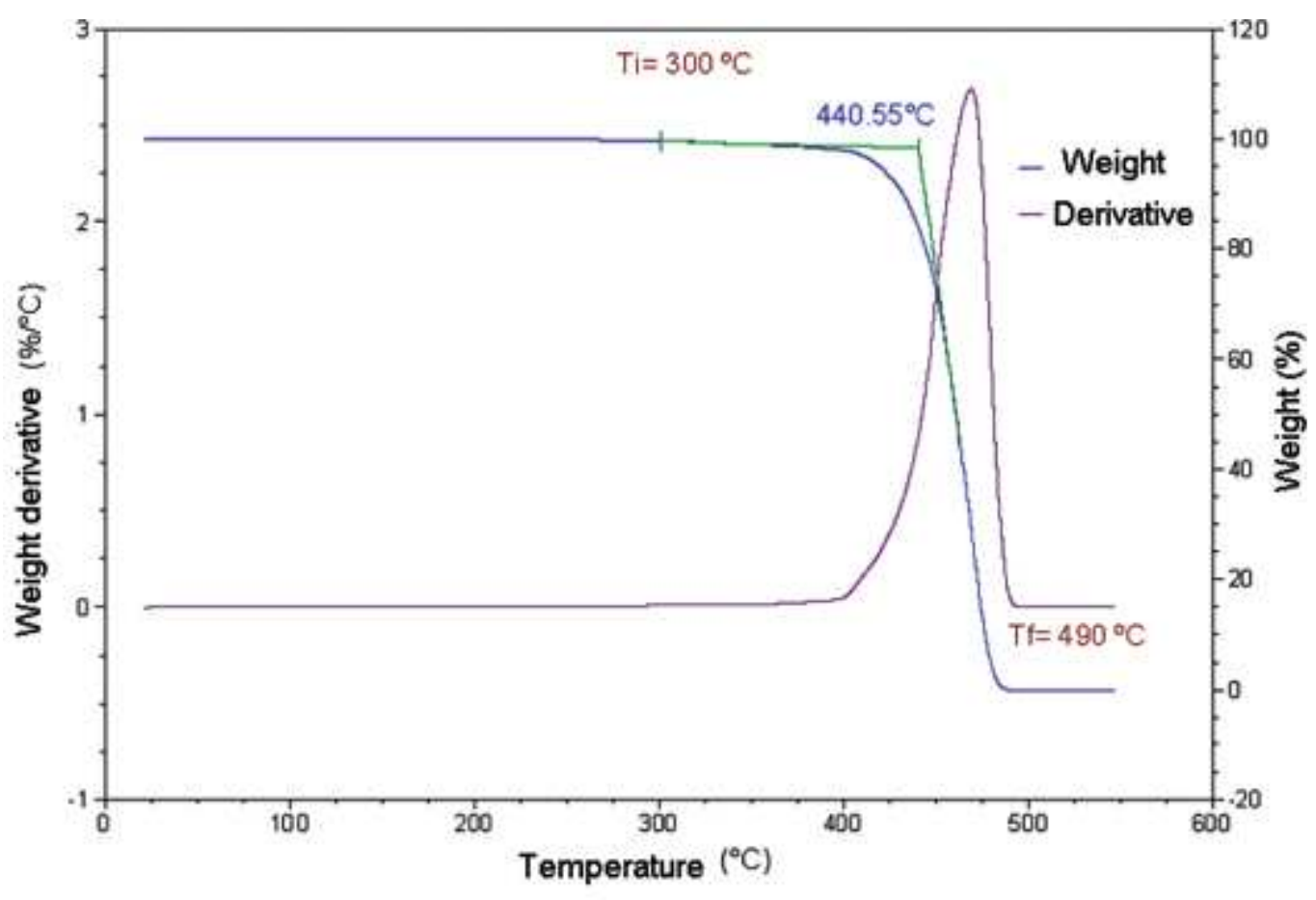

(a)

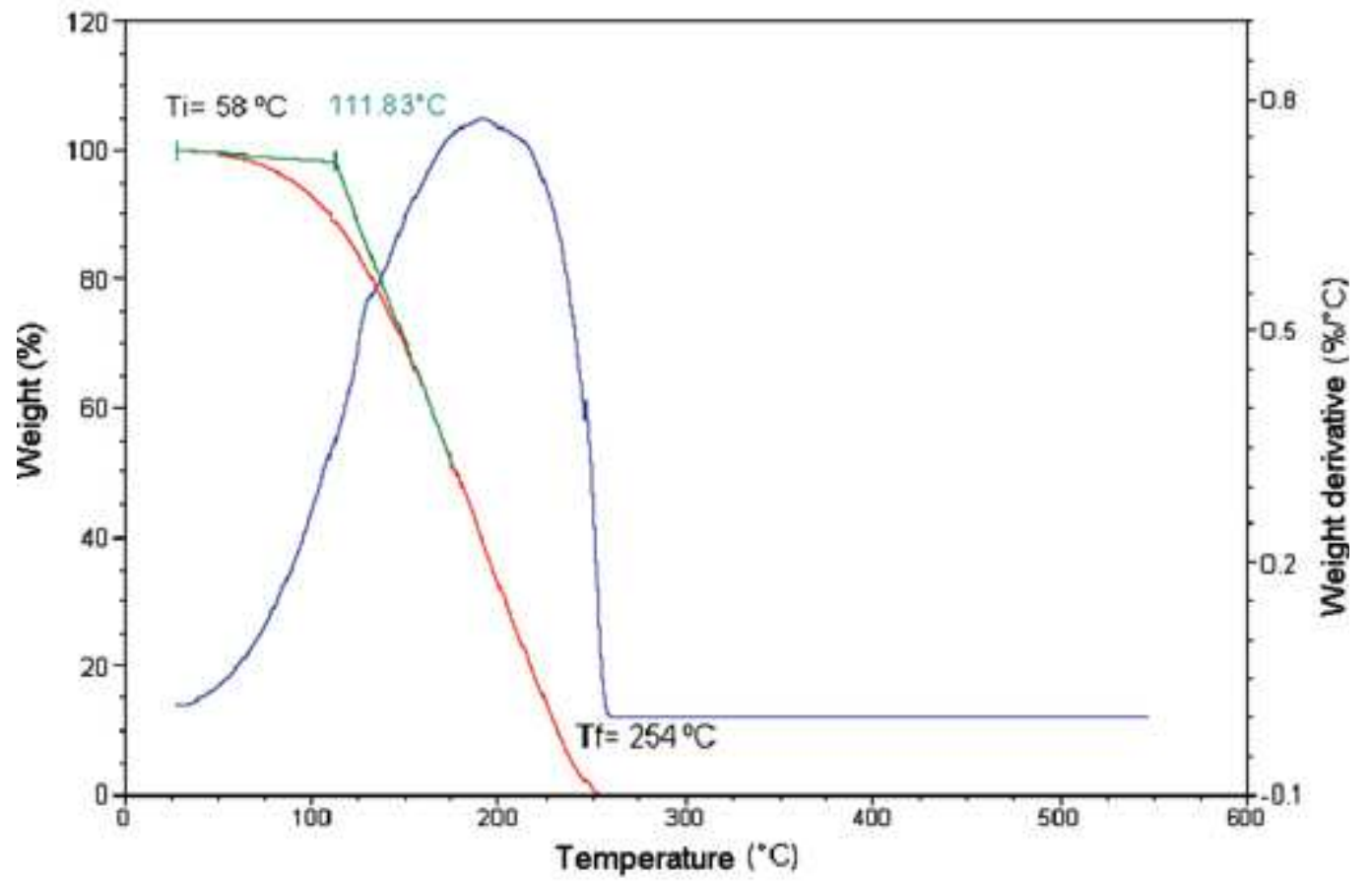

(b)

FIG. 2. Thermogravimetric analysis: a) As received HPDE; b) Diesel. 


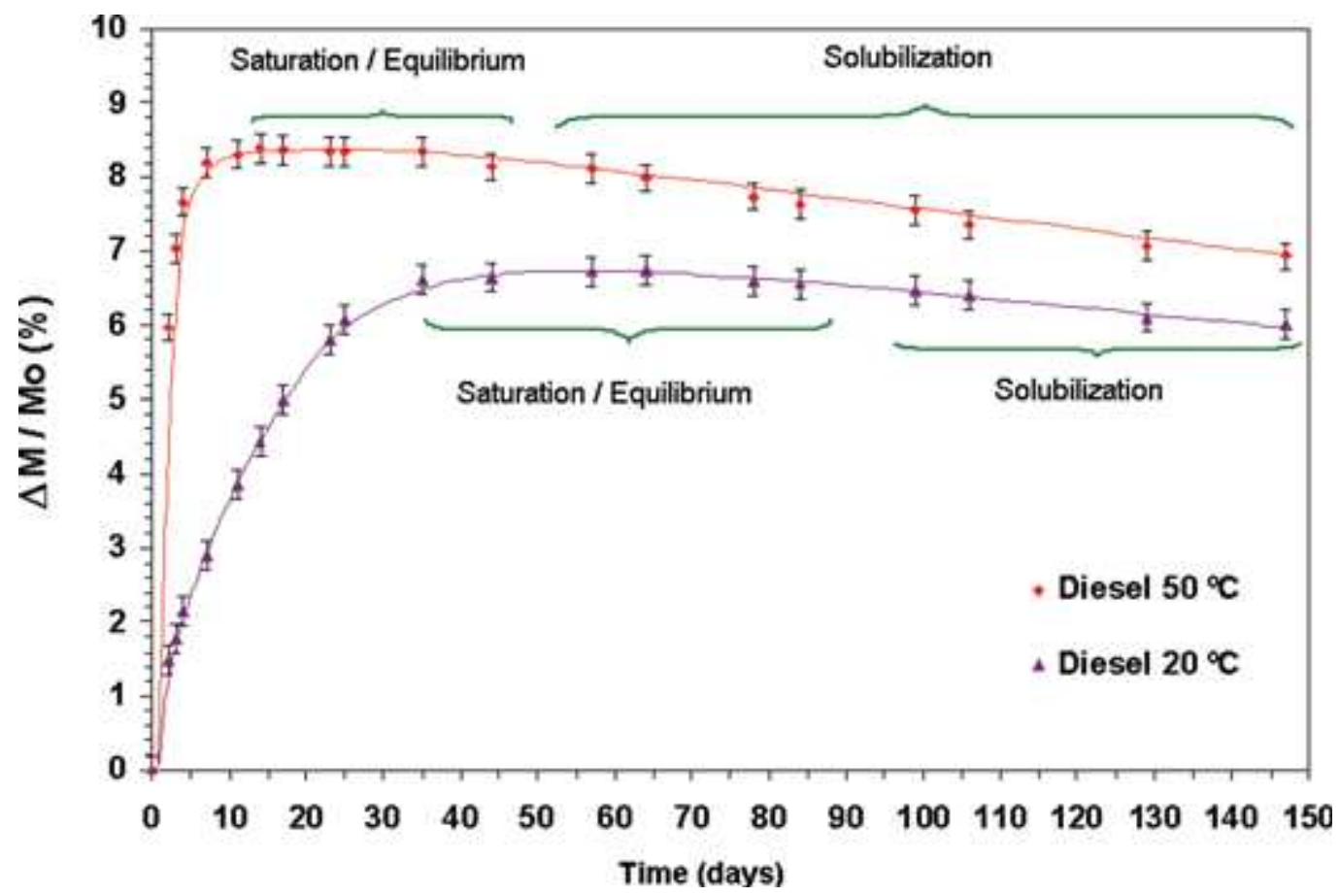

FIG. 3. Gravimetric analysis: absorption of diesel oil as a function of time and temperature. 


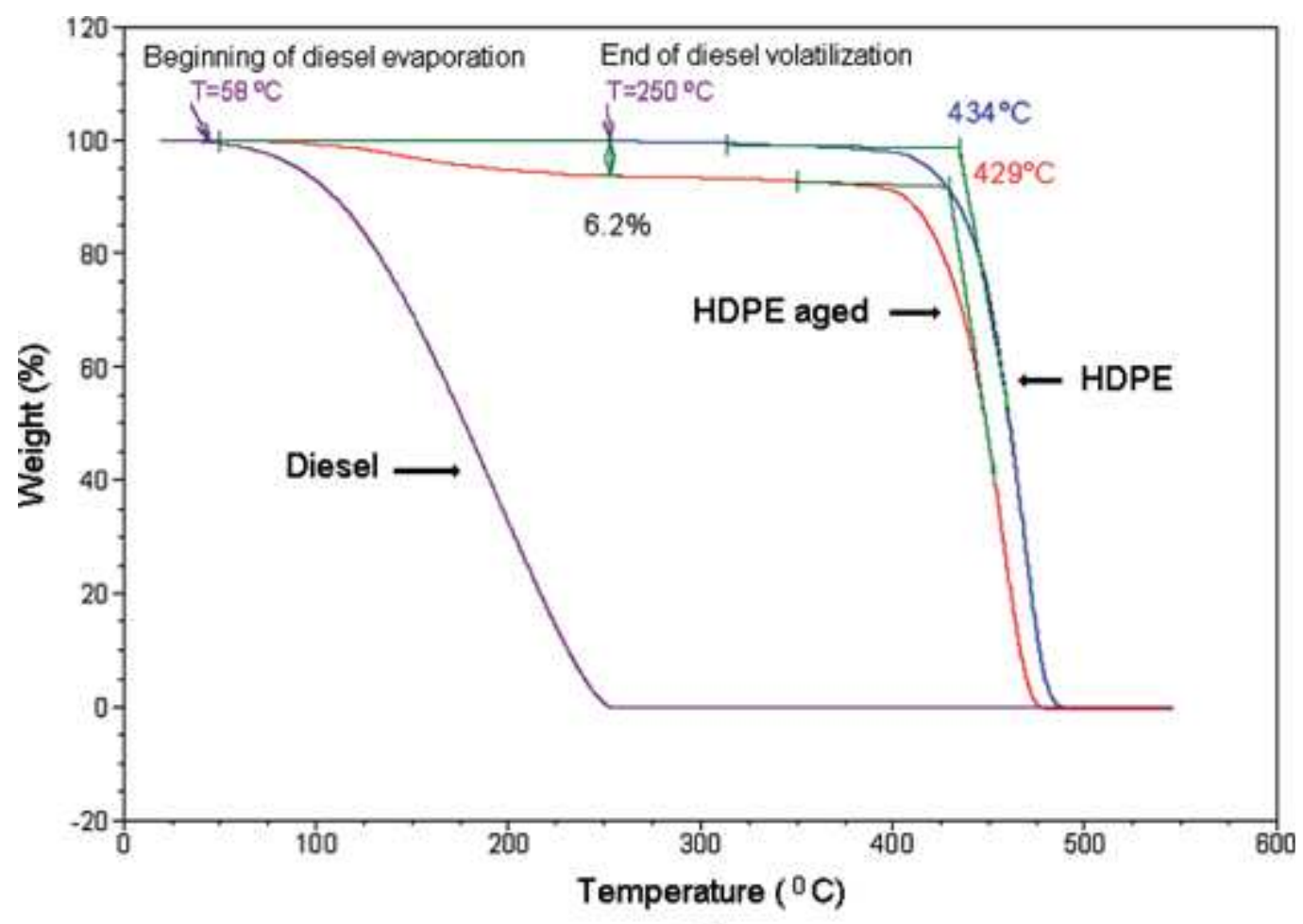

(a)

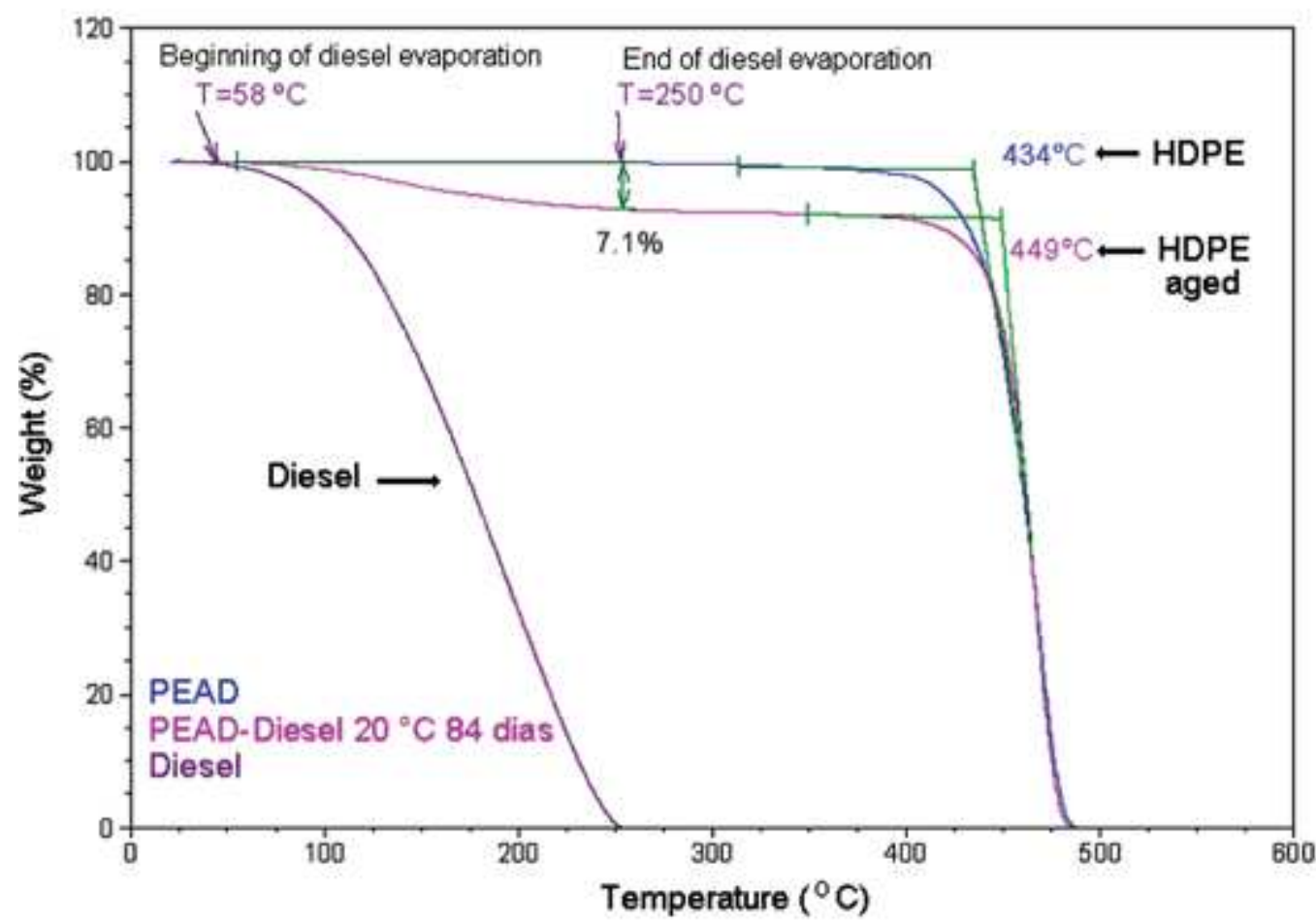

(b)

FIG. 4. Thermogravimetric curves obtained at $20^{\circ} \mathrm{C}$ after: a) 35 days of immersion, b) 84 days of immersion. 


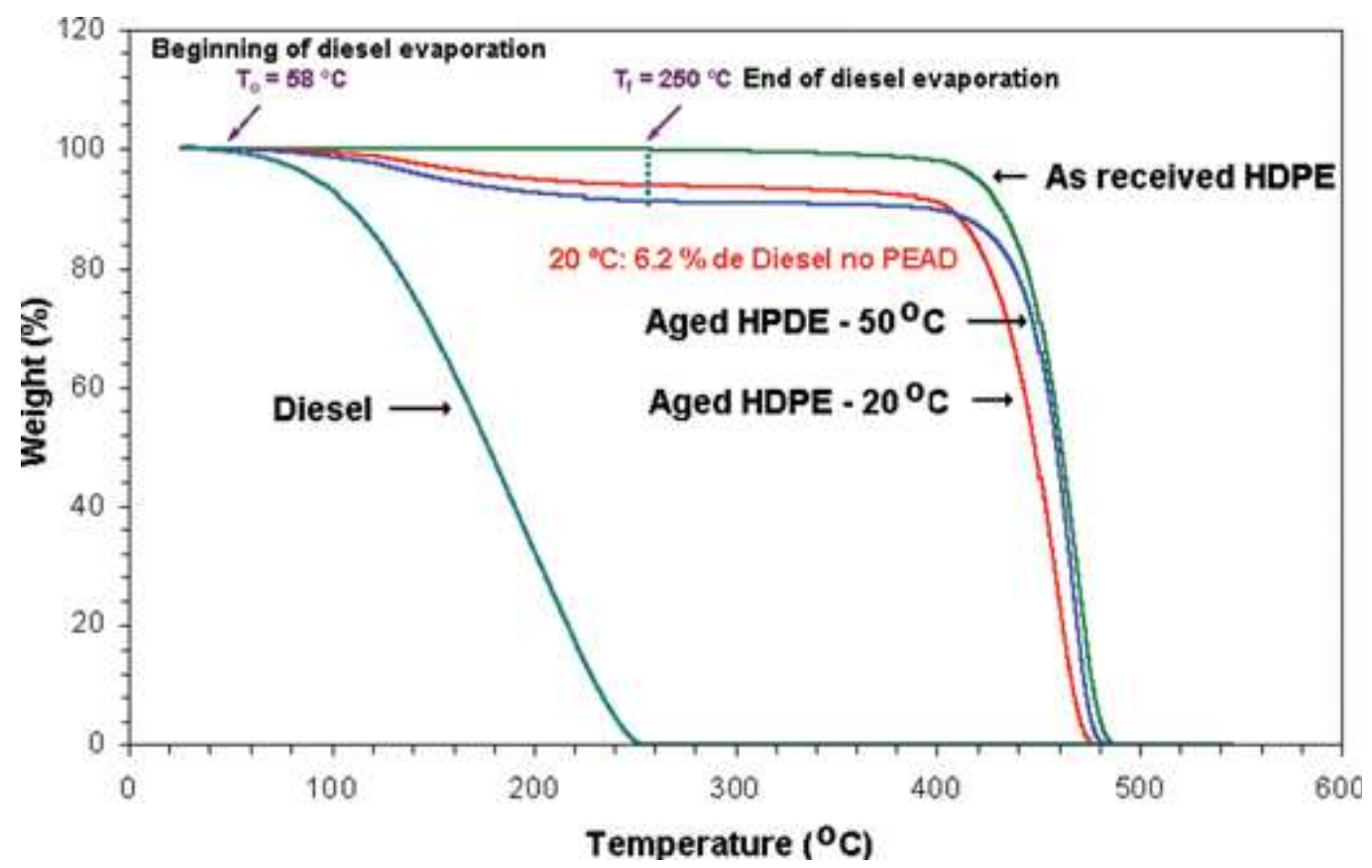

FIG. 5. Thermogravimetric curves for diesel aged HDPE at 20 and $50^{\circ} \mathrm{C}$. 


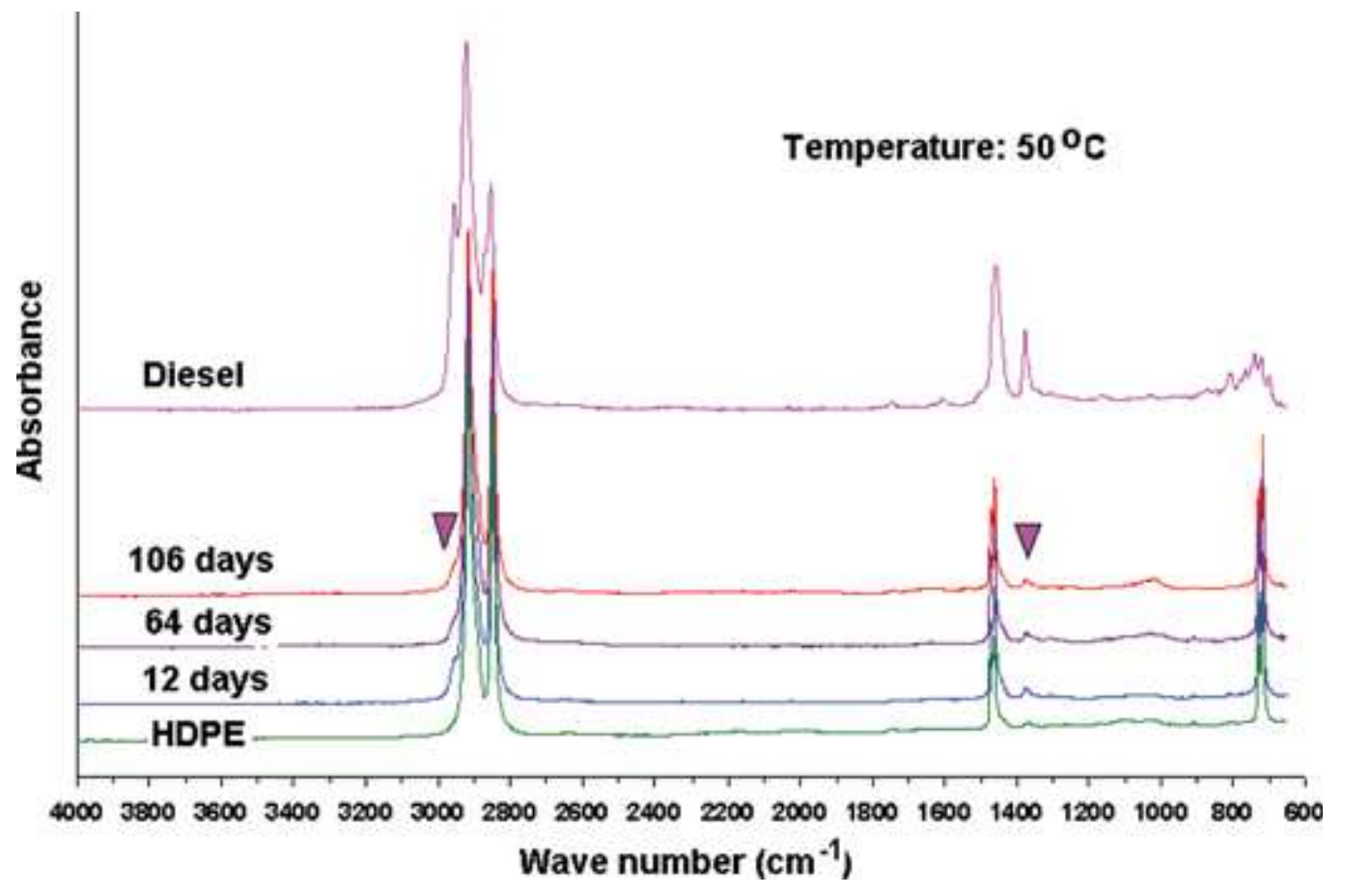

FIG. 6. FT-IR analysis of HDPE immersed in diesel at $50^{\circ} \mathrm{C}$, as a function of the immersion time 


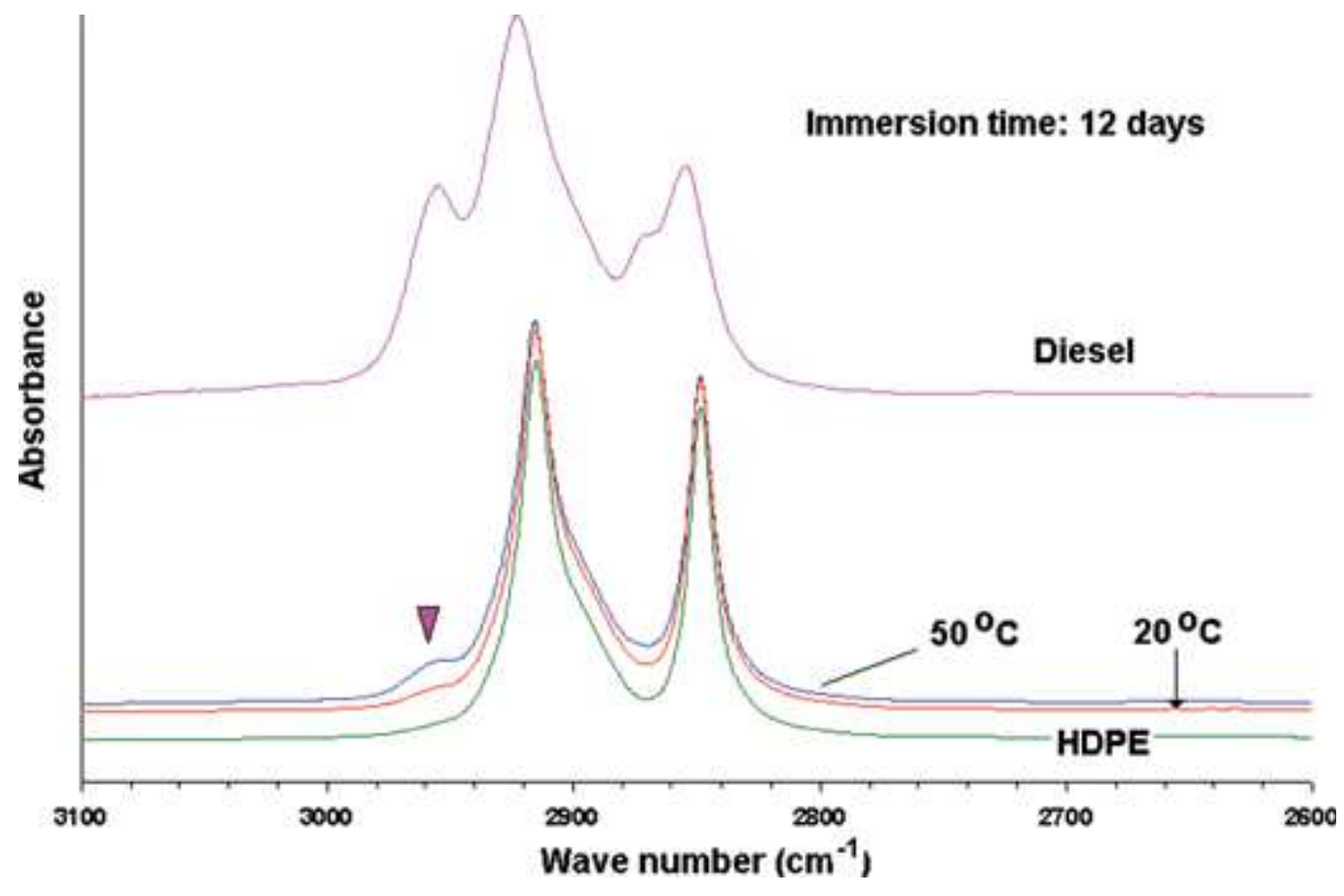

FIG. 7. FT-IR spectrum of the aged HDPE between $3100-2600 \mathrm{~cm}^{-1}$ showing the temperature effect. 